\title{
Prevention of C.A.D. in India - Newer insights [novel theory]
}

\section{Krishnamani NC* \\ Fortis Hospital, Shalimar Bagh, Delhi, India}

\section{Introduction}

Current projection suggests that India will have the largest cardiovascular burden in the world. Thirty percent of the deaths at present are due to heart disease. Not only the incidence is increasing but the disease - Coronary artery disease (CAD) is occurring in the young and presently more as Acute Coronary Syndromes advanced disease, diffuse disease and incidence is increasing in rural areas also [1]. The heart disease is occurring without any evidence of conventional or newer risk factors. The burning issue is to reach at the aetiology in our country so that adequate.

In spite of so much of research and studies the definite aetiology for CAD eludes us and our endeavor still continuous. Presently the conventional risk factors which have a proven aetiological role are Hypertension, Obesity, Dyslipidemia, Smoking, Diabetes, Sedentary life style, advancing age, positive family history and male gender [2,3]. The newer and emerging risk factors for CAD are Hyper homocystenemia, Hyper fibrogenemia, small dense LDL elevated LPA, Insulin resistance, inflammation and infection agents, psycho social factors, non-lipid related gene polymorphism and other miscellaneous factors, hemostatic and fibrinolytic abnormalities.

\section{Case observations}

Case 1: Acute Inferior Wall Myocardial Infarction (MI) and undergoing successful primary angioplasty and has uneventful recovery

Case 2: Acute Anterior Wall MI and cardiogenic shock. Coronary Angiography done showed thrombus in LMCA and whole of LAD and proximal circumflex. Even after successful thrombosuction and intracoronary thrombolytic therapy patient could recover from cardiogenic shock and died on day 2 of MI in spite all supportive therapy.

Case 3: Extensive anterior wall myocardial infarction, and echo showed Akinetic anterior wall with ejection fraction of $20-25 \%$. The coronary angiography showed $99 \%$ proximal LAD thrombotic occlusion. Immediate thrombosuction was done and primary stenting was done with drug eluting stent with good result.

Case 4: Acute Anterior Wall MI. Patient was hemodynamically stable, and echo showed akinetic anterior wall with LVEF of $40 \%$ and was taken up for primary PTCA. Coronary Angiography showed 100\% mid LAD occlusion and diffuse disease in LAD and RCA. After thrombosuction, the LAD lesion needed multiple ballooning because of hardened of the lesion and a drug eluting stent was successfully implanted in mid LAD.
Case 5: Extensive anterior wall MI Proximal LAD showed 100\% thrombotic occlusion and there was a mild lesion in the large OM. Successful PTCA with DES was done to proximal LAD. And was discharged on high dose statin ( $80 \mathrm{mg}$ atorvastatin) and prasugrel and aspirin along with other cardiac drugs. Patient was asymptomatic foe 2 months but started having typical symptoms for which antianginal drugs were stepped up. A check angiography showed a diffuse severe in-stent restenosis along with a prominent increase in the large OM lesion to $99 \%$ from a mild $20-30 \%$ lesion earlier.

On detailed evaluation there were no primary or newer coronary risk factors identified in any of the patients.

Personal history of all these cases gave clue to newer and interesting facts which may reveal the existing gaps in our present-day dilemma for CAD causation.

Case 1 started his carrier as an assistant in a plastic recycling factory and exposed to fumes of these plastics for more than 15 years. Later he had set up his own plastic recycling factory. He was not only exposed to plastic fumes but also used to chew these plastics as a habit.

Case 2 was a young dynamic salesman for more than 7 years with extensive two-wheeler driver across the Delhi city congested roads and consuming all roadside foods and extensive use of perfumes and deodorants.

Case 3 a young housewife is trained and has been running a beauty parlor at home for more than 9 years and has been handling cosmetics and other chemicals with hands and involved in making organic chemical [4-6].

Case 4 has been working at a shop supplying pesticides and insecticides for last 8 years and involved in manual mixing and spraying at different places.

Case 5 very fond of cold drinks and has been consuming very less amount of water and soft drinks, at least 4-5 crates of soft drinks per week for more than 20-25 yrs. This habit he continued even after the primary angioplasty

The common factors in all the 5 cases is the prolonged exposure to chemicals both in the form of organo chlorine, organo phosphorus, heavy metals, corrosives, and many undefined molecules [4-18].

All of these enter the body via skin, mouth, and by inhalations.

Correspondence to: Krishnamani NC, Fortis Hospital, Shalimar Bagh, Delhi, India, E-mail: Krishnamani_nc@yahoo.com

Received: November 20, 2017; Accepted: December 19, 2017; Published: December 23, 2017 


\section{Oxidative stress and endothelial dysfunction $[19,20]$}

- Oxidative stress lead to decrease in nitric oxide

- The decrease in nitric oxide is the first step in initializing endothelial dysfunction

- This leads to reduction of capacity of the endothelium to maintain homeostatis and leads to development of pathological inflammatory process and vascular trauma

- When the endothelium loses the capacity to keep balance it is invaded by lipids and leucocytes leading to fatty streaks

- Endothelial dysfunction and acute coronary syndrome

- Atherosclerosis is a diffuse disease and it is a inflammatory immunogenic polygenic and multifactorial disease

- Evidence from last ten years has shown that endothelial dysfunction plays a pivotal role. The atherosclerotic lesion always start as endothelial dysfunction and the quality and quantity of the plaque is directly depended on the deposition

- The quality is more important because it leads to rupture of the plaque which is the bases of acute coronary syndrome

- Increased intracellular and extracellular oxidative stress leads to endothelial dysfunction mainly via the nitric oxide mechanism

- Scientific and novel causative reason for CAD ---

--- Oxidants are slow toxins and the mechanism of them causing atherosclerosis is by endothelial dysfunction and by nitric oxide antagonism mechanism, then leading to a low grade and chronic inflammation.

\section{Final common pathway}

Billions of petrochemicals available which range from cosmetics, textiles, rubber, plastics, perfumes, insecticides and pesticides and other pollutants have been identified to cause oxidative stress by neutralizing the natural body antioxidants by nitric oxide mechanism. The oxidative stress results when the harmful free radicals or other prooxidants exceed over the cells antioxidant mechanism, disrupting the normal function. The different toxicity of different toxicants converge as the same common find pathway in the endothelial dysfunction leading to chronic inflammatory states.

\section{Hypothesis}

Low grade but constant exposure of various chemicals from various routes (which can be below toxic level as tested in labs before certifying safe for humans) are oxidants to the human tissues particularly to the endothelium. This endothelial dysfunction leads to chronic inflammatory state and may be the cause of increasing incidence of CAD, HT, DM, renal disorders and malignancies.

\section{Conclusions}

Time has come to understand the causes of CAD beyond the conventional and newer risk factors. Chronic oxidants exposure in the form of various petrochemicals, Aromatic compounds and other toxicants leads to oxidative stress which leads to endothelial dysfunction which further leads to chronic inflammation which can be factor.

\section{References}

1. Ajay VS, Prabhakaran D (2010) Coronary heart disease in Indian- Implications of the INTERHEART study. Indian. J. Med Res 132: 561-566. [Crossref]

2. Ali MK, Venkatnarayan, Tandon N (2010) Diabetes and Coronary heart disease- current perspective. Indian J Med Res 132: 584-597. [Crossref]

3. Sharma M, Ganguly NK (2005) Premature Coronary Artery Disease in Indians and its associated risk factors. Vasc Health Risk Manag 1: 217-225. [Crossref]

4. Beychd M (2011) The Encyclopedia of Earth:- Physics and Chemistry. Petrochemicals 756-784.

5. Betkin DB (2010) Environmental effects of petroleum. In. A Scientist guide to energy independence- oil; Pearson Education, pp. 11-13.

6. Pani B (2015) Polymers for environment. In: Textbook of Environmental Chemistry K. International Pvt ltd. pp. 447-457.

7. Aguilar G, Mazzamarr. G, Rasberger M (2011) Oxidative degradation and stabilization of mineral oil based lubricants. In: Chapter 4. Chemistry and Technology of lubricants; Roy-M.Mortier, Malcolm F Fox Stefan. T. Orszuuk (3rd Edn.) Springer Science. pp 107-146.

8. Re TA, Beach DM, Steven G. Nitka (2010) In. Toxicology in cosmetics, chapter 5, The Chemistry and maintenance of cosmetics, Vol. 1, Ed. Mithell Schlossman, 4th Edn. pp $181-206$

9. Drugs and Cosmetics (IInd Amendment) rules (2005) Govt of India. Ministry of Health and Welfare, Notification, pp.7-37.

10. Turin L, Sanchez T (2009) In: Perfumes- Chemistry and art, Perfumes A- Z guide Paperback. pp 33-40.

11. PYBUS D, Sell C (1999) In: Ingredients for the Modern Perfumery Industry, Chapter 4, In: The Chemistry of fragrances complied by David PYBUS and Charles Sell, RSC paperbacksed pp 5-124.

12. Brydson JA (1999) The chemical nature of Plastics. In: Chapter 2, Textbook Plastic materials, seventh edition. pp. 19-42.

13. Tilus AM, Sagati M (2013) In: Stabilizers and Food Additives Chapter 3, (3.1 to 3.5) sweeteners - chapter -4 , (4.1 to 4.6). Flavouring agents- chapter 5, (5.1 to 5.5). Food colour and colour retention agents - chapter $-7,(7.1$ to 7.7$)$. In: Chemistry of food additives and Preservatives, wiley Blackwell.

14. Vartanian LR, Schwatz MB, Brownell KD (2007) Effects of soft drinks consumption and nutrition and health. A systematic Review and meta analysis. Am J Public Health 97: 667-675. [Crossref]

15. Johnson S, Sakia N, Kumar A (2006) Analysis of pesticides residues in soft drinks, CSE Report.

16. Kluwer (1988) In: Fertilizers - Gen concepts, classification, terminology and defination In: chapter-1 Fertilizer Mannual- Unted Nations Industrial development organization. pp. 1-18.

17. Srivastava S, Goyal P, Srivastava MM (2010) Pesticides - Past, present and future pp. 47-62, Handbook of Pesticides; Les ML Nollet and Harmir Singh Rathore, CRC press. pp 47-62.

18. Hoftoon RV (2004) In: chapter 2, pp 13-74; Chemical Oxidation. In. The Mechanism and applications of chemical oxidants for renewal purposes, Chemistry Textbook; Wiley- Inter science. pp 13-74.

19. Deanfield JE, Halcox JP, Rabelint TJ (2007) Endothelial function and dysfunction. Circulation 115: 1285-1295. [Crossref]

20. Haitzer T, Schilinziq T, Krohn K (2003) Endothelial dysfunction, oxidative stress and risk of cardiovascular events in patients with coronary artery disease, Circulation 108 : 500-508.

Copyright: (C)2017 Krishnamani NC. This is an open-access article distributed under the terms of the Creative Commons Attribution License, which permits unrestricted use, distribution, and reproduction in any medium, provided the original author and source are credited. 